\title{
Focus on co-management in geriatric fracture care
}

\author{
M. Knobe ${ }^{1}$ H.-C. Pape ${ }^{1}$
}

Received: 26 May 2016 / Accepted: 30 May 2016 / Published online: 24 August 2016

(C) Springer-Verlag Berlin Heidelberg 2016

Dear colleagues,

Geriatric trauma care is gaining more importance due to demographic changes.

The number of geriatric fractures in Germany in 2011 was already as high as 720,000 and will increase by an estimated $28 \%$ until the year 2030 [1]. This growth in geriatric trauma patients presents a great challenge for the treating physicians. In addition to poor bone quality which makes (operative) fracture fixation more difficult, comorbid conditions often lead to perioperative complications and hamper rehabilitation. Considering all these factors, geriatric trauma has great social and economic implications [2]. The Editors of the European Journal of Trauma and Emergency Surgery are therefore to be commended for this special issue dedicated to the complex co-management in geriatric fracture care including fall prevention and new interdisciplinary developments like installation of a fracture liaison service or a geriatric fracture center.

The incidence of falls in the elderly population is difficult to determine and therefore potentially underestimated. Previous falls, strength, gait and balance impairments, and use of specific medications range amongst the strongest predictors [3]. By identifying individuals with a high risk of falling, targeted fall prevention interventions could be directed at those most likely to benefit from them. The first article in this issue highlights the importance of the detailed evaluation of different assessment tools and introduces a new mobility and balance index into practice comparing it with the established Tinetti Scale [4].

M. Knobe

mknobe@ukaachen.de

1 University of Aachen Medical Center, Aachen, Germany
Proximal femoral fractures have the greatest economic impact among osteoporosis-related fractures [5]. Muhr and Tscherne already pointed out the importance of adequate treatment of trochanteric femoral fractures in geriatric patients 30 years ago. The authors identified instability, osteoporosis and the requirement of early mobilization as the key factors and main problems in the treatment of these fractures [6]. However, other factors like a chronic proinflammatory status also contribute to the patient outcome, called "inflammaging" [7]. In elderly patients the immune system is significantly compromised even in absence of injury. Despite growing interest in these topics the immunological relevance of individual surgical strategies has not been resolved. The paper by Thaeter et al. deals with the perioperative inflammatory response in major fracture and its dependence on age [8].

Malnutrition, sarcopenia and frailty lead to the functional impairment and are part of a vicious circle. Despite the high rate of malnutrition among elderly trauma patients and its influence on outcome, standardized preoperative nutritional assessment is lacking in most centres [9]. Eschbach et al., with their contribution in this issue, developed a web-based questionnaire, seeking information regarding the use of nutritional assessments, and the use of defined laboratory parameters for detection of malnutrition [9].

Osteoporosis, besides age-related gait disorders, represents the primary risk factor for femoral fractures in old age. Due to the osteopenic bone structure even minimal trauma leads to sometimes complex fractures of a type rarely found in younger patients [10]. Implant fixation in osteoporotic bone presents a dilemma for the orthopaedic surgeon and lead to the development of new fixation techniques [11]. At present there is no established comprehensive treatment guideline for osteoporosis. 
In this context, colleagues Schray et al. give us their highly respected opinion on the "value of a coordinated management of osteoporosis via a fracture Liaison service for the treatment of orthogeriatric patients" [12].

Different types of co-managed care have been developed in many places to help elderly patients to regain selfdependence. Close collaboration with geriatricians creates synergies to face problems such as postoperative delirium, nutrition, pain management, wound care and fall prevention. While there is a tendency to a better overall result in patients receiving multidisciplinary inpatient rehabilitation, the literature is inconsistent [13]. There is also no consensus on the efficacy of the different orthogeriatric models [14]. However, because of an improved short-time mobility it was suggested that the treatment of older patients with hip fractures should be organized as orthogeriatric care [15]. The problem is to identify those patients, using several assessment strategies, who will profit from these cooperations. Cost-effectiveness of these programs will also have to be considered. For this reason, the contribution of Basu and Kates from the Virginia Commonwealth University is a highlight in this focus issue giving us his experience in the development of a geriatric fracture center in Richmond (Virginia, USA) [16].

The initiative of the German Society of Trauma Surgery (Deutsche Gesellschaft für Unfallchirurgie, DGU) to create a certification procedure for geriatric trauma centers (Alters Trauma Zentrum $\mathrm{DGU}^{\circledR}$ ) and to establish a geriatric trauma registry for hip fractures (Alters Trauma Register DGU ${ }^{\circledR}$ ) serves as a quality measurement tool and will be able to answer these questions in the future. Besides, it forms the basis for fundamental and innovative projects in the field of health services research.

Up to date there are 30 certified geriatric trauma centers and numbers are rising exponentially.

We would like to thank all contributing authors for their fine papers and their highly appreciated effort and wish the concerned colleagues, an interesting time reading the articles of this focus.

Kind regards

Matthias Knobe, Guest Editor

Hans-Christoph Pape, Guest Editor

\section{Compliance with ethical standards}

The authors comply with the ethical guidelines for authorship and publishing in the European Journal of Trauma and Emergency Surgery. This article does not contain any studies with human or animal subjects performed by the author.
Conflict of interest Matthias Knobe and Hans-Christoph Pape declare no conflicts of interest in relation to this work.

\section{References}

1. Ström O, Borgström F, Kanis JA, Compston J, Cooper C, McCloskey EV, Jönsson B. Osteoporosis: burden, health care provision and opportunities in the EU: a report prepared in collaboration with the international osteoporosis foundation (IOF) and the European federation of pharmaceutical industry associations (EFPIA). Arch Osteoporos. 2011;6:59-155.

2. Singer A, Exuzides A, Spangler L, O'Malley C, Colby C, Johnston K, Agodoa I, Baker J, Kagan R. Burden of illness for osteoporotic fractures compared with other serious diseases among postmenopausal women in the United States. Mayo Clin Proc. 2015;90:53-62.

3. Tinetti ME, Kumar C. The patient who falls: it's always a tradeoff. JAMA. 2010;303(3):258-66.

4. Knobe M, Giesen M, Plate S, Gradl-Dietsch G, Buecking B, Eschbach D, van Laack W, Pape HC. The Aachen mobility and balance index to measure physiological falls risk: a comparison with the Tinetti POMA Scale. Eur J Trauma Emerg Surg. 2016. doi:10.1007/s00068-016-0693-2.

5. Burge R, Dawson-Hughes B, Solomon DH, Wong JB, King A, Tosteson A. Incidence and economic burden of osteoporosisrelated fractures in the United States, 2005-2025. J Bone Miner Res. 2007;22:465-75.

6. Muhr G, Tscherne H, Thomas R. Comminuted trochanteric femoral fractures in geriatric patients: the results of 231 cases treated with internal fixation and acrylic cement. Clin Orthop Relat Res. 1979;138:41-4.

7. Franceschi C, Capri M, Monti D, Giunta S, Olivieri F, Sevini F, Panourgia MP, Invidia L, Celani L, Scurti M, Cevenini E, Castellani GC, Salvioli S. Inflammaging and anti-inflammaging: a systemic perspective on aging and longevity emerged from studies in humans. Mech Ageing Dev. 2007;128(1):92-105.

8. Thaeter M, Knobe M, Vande Kerckhove M, Boehle F, Verhaven E, Pape HC. Perioperative inflammatory response in major fracture-do geriatric patients behave differently?. Eur J Trauma Emerg Surg. 2016. doi:10.1007/s00068-016-0719-9

9. Eschbach D, Kirchbichler T, Oberkircher L, Knobe M, Juenemann M, Ruchholtz S, Buecking B. Management of malnutrition in geriatric trauma patients: results of a nationwide survey. Eur J Trauma Emerg Surg. 2016. doi:10.1007/s00068-016-0698-x.

10. Ouanes JP, Tomas VC, Sieber F. Special anesthetic considerations for the fragility fracture patient. Clin Geriatr Med. 2014;30:243-59.

11. Knobe M, Nagel P, Maier KJ, Gradl G, Buecking B, Sönmez TT, Modabber A, Prescher A, Pape HC. Rotationally stable screw-anchor with locked trochanteric stabilizing plate versus proximal femoral nail antirotation in the treatment of AO/OTA 31A2.2 fracture: a biomechanical evaluation. J Orthop Trauma. 2016;30(1):e12-8.

12. Schray D, Neuerburg C, Stein J, Gosch M, Böcker W, Kammerlander C. Value of a coordinated management of osteoporosis via fracture liaison service for the treatment of orthogeriatric patients. Eur J Trauma Emerg Surg. 2016. doi:10.1007/s00068-016-0710-5

13. Handoll HH, Cameron ID, Mak JC, Finnegan TP. Multidisciplinary rehabilitation for older people with hip fractures. Cochrane Database Syst Rev. 2009;7(4): CD007125. 
14. Kammerlander C, Roth T, Friedman SM, Suhm N, Luger TJ, Kammerlander-Knauer U, Krappinger D, Blauth M. Ortho-geriatric service-a literature review comparing different models. Osteoporos Int. 2010;21(Suppl 4):637-46.

15. Prestmo A, Hagen G, Sletvold O, Helbostad JL, Thingstad P, Taraldsen K, Lydersen S, Halsteinli V, Saltnes T, Lamb SE,
Johnsen LG, Saltvedt I. Comprehensive geriatric care for patients with hip fractures: a prospective, randomised, controlled trial. Lancet. 2015;385(9978):1623-33.

16. Basu N, Natour M, Mounasamy V, Kates SL. Geriatric hip fracture management: keys to providing a successful program. Eur J Trauma Emerg Surg. 2016. doi:10.1007/s00068-016-0685-2. 